\title{
Return from COVID-19: Thinking Differently About Export Competitiveness and Sustainability
}

\author{
Kirankumar S. Momaya ${ }^{1}$ (D) \\ Published online: 7 August 2020 \\ (c) Global Institute of Flexible Systems Management 2020
}

\begin{abstract}
Times are really tough for millions across the world, and more so for poor populations in emerging countries, due to the strategic discontinuity called COVID-19. This perspective editorial urges to think differently in addressing issues such as the COVID-19 pandemic. Starting from an analogy of 'signals from nature', it gives a brief background about the relationship between competitiveness and sustainability. The classical method of situation-actor-process-learning-action-performance (SAP-LAP) is adapted for the context of an experimental bottom-up micro-pilot to 'Return from COVID-19'. Glimpses of emerging findings from the pilot project in the context of academic institutions are shared. Topics for urgent and mid-term studies in the given context are listed, focusing on implications for the rebound of export activity. We will discuss ways for leaders to enhance export competitiveness despite COVID-19. This article contributes to the literature by extending SAPLAP in an alternative micro-situation for an optimistic scenario.
\end{abstract}

Keywords Export competitiveness · Sustainability · आत्मनिर्भरता · Learning from nature · Cooperative strategies · Action research $\cdot$ SAP-LAP scenario

We have sufficient for everybody's needs, Not for Greed.-Mahatma Gandhi (1960, p. 3)

\section{Sensing Signals from Mother Nature}

Mother nature has for decades been very accommodating to the greed of many, but recent crises signal that 'limits to growth' (Meadows et al. 2004) may have been reached quite a while ago. Responses to silent crises such as pollution and climate change have been too slow, and the most powerful countries often threaten to withdraw from collective organizations. However, responsible cities or states may proactively start to address challenges. For instance, Leaders in London, New York and Tokyo have taken several initiatives to stabilize population, de-congest, reduce pollution and help the city on the journey of rejuvenation. Leaders in Indian cities have also tried, but may be less proactive and

Kirankumar S. Momaya

momaya@iitb.ac.in

1 Shailesh J. Mehta School of Management, Indian Institute of Technology Bombay, Mumbai 400 076, Maharashtra, India effective. A crisis such as COVID-19 can be interpreted as a signal from Mother Nature that we need to rethink with a clean slate about the fundamentals of economy, development and sustainability.

While most of us see many challenges arising from COVID-19, some of us should also be able to sense the signals and see opportunities to review directions. In an Indian context, examples of macro challenges include finding incomes for youth and experienced workers (e.g. made jobless due to crisis), restarting supply chains to fill voids and restoring health (not only physiological, but psychological as well). Similarly, examples of competitiveness challenges at a firm level include regaining customers (particularly international ones at better price points), and innovating to address problems, even if we assume that operational challenges can be managed-which may not be true for many firms. Proactive firms or organizations can reboot ideation by asking tougher questions, such as the following in the context of the Indian Institute of Technology Bombay (IITB):

- How long will the air in cities remain reasonably clean? Can it become even worse in Mumbai post-lockdown for reasons such as the following: 
- Many people are adopting road travel, as trains-the backbone of public transport-in Mumbai are considered less safe in such a crisis.

- How can Mumbai trains achieve new levels of hygiene to be among the safest public transport in India, not only from COVID-19, but other types of infectious diseases (e.g. tuberculosis) as well?

- When can we dream of bicycling beyond the IITB campus-a paradise for walkers and bicyclists-and attend meetings within a 5-50-km range from IIT Bombay, riding on bicycles in case public transport systems become less safe due to such viruses?

- How can we pilot greener labs or gemba that are more resilient, to help 'return from crisis' at even better sustainability?

- What types of new service or product development (NSD or NPD) and organizational innovations should be piloted at IITs to enhance contributions to society, industrial competitiveness (Momaya et al. 2017) and exports in an $\mathrm{X} / 5$ scenario of resources (e.g. only $1 / 5$ resource available)?

\section{Sustainability and Competitiveness}

The low sustainability of popular schools of development and economics has been highlighted by many in India, and is now confirmed by strategic discontinuities (SDs) such as COVID-19. Mahatma Gandhi long ago rejected the Westerndominant design of development and took several initiatives with holistic approaches balancing socioeconomic, health, political and other dimensions (e.g. गांधी १९२१). Most of the large Asian countries that broke out into higher orbits significantly adapted some development model, and if not, invented their own.

Similarly, new thinking is needed on the competitiveness front to minimize losses for firms, ventures, clusters and cities from such strategic discontinuities (SDs). Paradigms such as industrial organization (IO) and the Porter Diamond (Porter 1990) will remain popular, but may be of limited use to address the survival crisis of competitiveness being faced by a large number of start-ups, micro-, small and medium enterprises (MSMEs), ventures and even focal firms (Momaya 2016). For instance, it is forecasted that more than $45 \%$ of the Indian population will fall below the poverty line as a result of COVID-19 (CII 2020). The huge task of lifting them out of poverty again will be daunting; what took decades to build will be wiped out with just one crisis, and India may not have the resilience of countries such as Japan and Korea needed to recover. Developing countries such as India do not have deep pockets, and indebtedness can skyrocket for individuals, MSMEs, firms, cities and even countries that fail to sustain competitiveness. This indicates that popular models of development and competitiveness are less sustainable.

Alternative thinking on competitiveness has begun to yield more flexible and useful frameworks. For instance, models such as ABCD [Advantages,Benefits, Constraints, Disadvantages] (Yin et al. 2019) have higher utility due to simplicity. The competitiveness assets-processes-performance framework (APP) (Momaya 2001) has a very strong 'process' facet that can help prioritize linkages of different factors (e.g. competitiveness asset factors such as human and financial resources) to sustain performance on key factors of survival (e.g. employee satisfaction, cashflow) and prepare firms to scale up on other factors, including performance, once the firm has navigated through multiple valleys of death (MVoD). Apart from sound foundations, attempts have been made to incorporate the best elements of classical theories such as the resource-based view (RBV) and the dynamic capabilities view (DCV) in a competitiveness APP framework, and such approaches are being tested in a variety of industries, from mature (e.g. engineering construction, Bhattacharya et al. 2009) to emerging ventures (e.g. software, Shee et al. 2001, Ambastha et al. 2004; telecom, Mittal et al. 2013; nanotechnology, Momaya 2008).

The sustainability dimension of competitiveness is also important, but may need to wait a bit, as return from COVID-19 has become the first priority for most governments, industry associations, firms and even institutes.

Let's make some sense of examples of brutal facts to understand weak signals.

Examples of signals from nature or facts:

- Cities and towns are getting choked with traffic, solid and liquid waste, increasing pollution

- Shrinkage or disappearance of lakes, ponds, forests, flora, fauna and other forms of life

- Worsening fiscal and trade balance (if not savings, investments, information, knowledge, technology, etc.)

- Pollution of core or surrounding cities and towns (from air and water to solid waste)

- Lack of balance: e.g. in levels of self-sufficiency, low energy

\section{Key Questions and Methods}

In the context of the background highlighted above, we want to address practical questions such as:

- How can MSMEs, firms and institutions return from strategic discontinuities such as COVID-19 with higher flexibility? How can we enhance sustainability and export competitiveness? 
- What are the advantages and limitations of bottom-up or grassroots projects that can help increase the confidence and motivation of associates?

- What can we learn from such micro-projects? How can we share them to benefit many?

Considering the urgency of the situation, we adopted an action research approach (Kemmis et al. 2013) as a research method to address the situation and improve the classical SAP-LAP framework (Sushil 2001). SAP-LAP is a very useful holistic framework that has been evolving through applications in diverse contexts, including one related to technology management and competitiveness (e.g. Sahoo et al. 2010). Since a key objective of our action research (AR) is to address problems created by the strategic discontinuity, we explored various types of SAP-LAP models. In this way, we aimed to evolve a specific model for problem solving, building on tools such as problem structuring (Momaya et al. 2017). The model will be an exploratory one (versus normative, Sushil 2001) for managerial inquiry (and later, case development) for a specific context of the 'Group on competitiveness' (GoC). We take into consideration the six components of SAP-LAP (please refer to details of each component in the Appendix) and plan to make a method contribution by extending SAP-LAP. We plan to consider a future scenario of changed situations to sharpen priorities among actors and actions for higher feasibility.

Among different types of action research (AR), we adapted selected elements of canonical AR with a focus on problem solving. Researcher intervention to improve situations in times of crisis such as COVID-19 also envisage change (e.g. Wong and Davison 2018) through action research on multiple dimensions:

- Flexibility and resilience to get up and 'return from crisis' with better performance.

- It is a cooperative project, where the $\mathrm{GoC}$ intends to contribute significantly to recovery of research processes at multiple levels, from $\mathrm{GoC}$ to other research groups at the management school—our clients for internal counselling. Since the crisis has hit at a time when the school is in 'Silver Jubilee' year, the time is right for deep thinking.

- In terms of theory, we will build on problem solving theory, particularly structured methods such as problem structuring that are found to have flexibility to interface well with the SAP-LAP framework, e.g. through actorbased root cause analysis (RCA) (for an example in a very related context of IITs, please see Momaya et al. 2017) to enhance the feasibility of actions.

- We focus on the collaborative aspect of canonical AR. The actors here are researchers at the management school, particularly associates of the $\mathrm{GoC}$, who have shown a keen interest in actively participating in the project. We also plan to emphasize improving rigour (the other element of canonical AR, Davison et al. 2004; Wong and Davison 2018).

Since it was not possible to meet associates in person, alternative e-meeting approaches were adopted to coordinate actions during the lockdown. For documenting the situation, processes, etc., we employed and extended a powerful structured SAP-LAP approach (Sushil 2001) that has been widely used. We attempt to extend the SAP-LAP framework by:

- Testing its utility in a sharper focus on the micro-context of small groups

- Evolving an alternative situation as a guide to concentrate on future actions and performance. We used an optimistic scenario of a future situation.

\section{Glimpse of Emerging Learning from Pilots}

The COVID-19 tsunami that swept across the world will be felt for decades. With cases close to five million, the death toll has surpassed 325,000 (as of May 20 and we are still countig; Worldometers 2020). The big question is why the developed countries were so ill-prepared, and have seen more than 8000 deaths each (e.g. Germany 8193, France 28,002, UK 35,341 and USA 93,533; as of May 20, 2020, Worldometers 2020). A glimpse of patterns of new cases in selected large countries is given in Fig. 1. A comparison of patterns among the largest countries (by size of the economy) provides some useful findings. The scale of the $y$-axis-daily new cases, considered a good proxy for effectiveness-gives a clue to different scales of impact in these countries. The USA has been the worst affected in this early phase, with new cases per day peaking at close to 40,000 and very slow declines; the death toll in the USA is higher than that during WW II. Japan was able to contain the peak below 1000 , a more than 20 -fold difference compared with the peak in the USA, after factoring in the population difference.

Patterns are quite different for India, Japan and the USA; China may remain an exception. India's peak has not yet been reached. The focus on saving human lives in India seems to be quite different from the focus in the USA (more focus on economy), but India may have to endure massive economic losses for much longer. China may remain an exception; it was able to contain the pandemic dragon much more rapidly.

Within India, megacities are the worst affected, and patterns are quite divergent and dynamic. Population densities in megacities are reaching alarming levels, and they can become easy victims of such pandemics. Mumbai and Pune seem to be the worst affected among the diverse patterns 

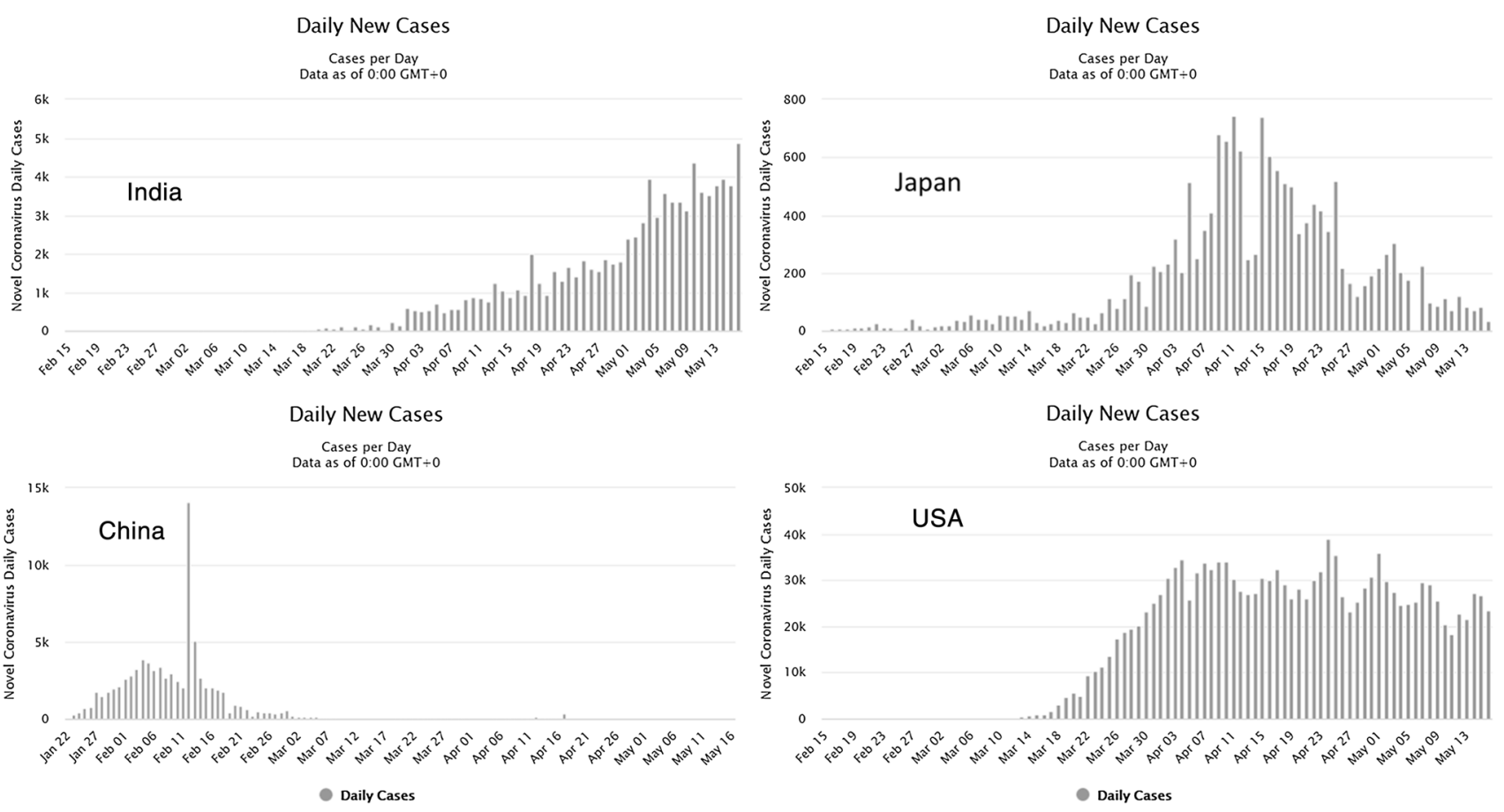

Fig. 1 Divergent patterns of new cases of COVID-19 among selected large countries. Source: Adapted from https://www.worldometers.info/ coronavirus/; last accessed on May 20, 2020

Table 1 Glimpse of patterns of COVID-19 cases in selected cities in India

\begin{tabular}{lrrccl}
\hline Megacity & Confirmed & Active & Recovered & Deceased & Population \\
\hline Bengaluru & 20.03 & 8.53 & 10.67 & 0.71 & $8,436,675$ \\
Chennai & 650.70 & 565.47 & 79.90 & 5.34 & $4,681,087$ \\
Hyderabad & 91.63 & 54.33 & 34.21 & 3.08 & $6,809,970$ \\
NCR Delhi & 573.95 & 384.27 & 183.51 & 6.18 & $11,007,835$ \\
Mumbai & $\mathbf{9 7 5 . 8 6}$ & $\mathbf{7 8 8 . 6 8}$ & $\mathbf{1 5 0 . 0 5}$ & $\mathbf{3 7 . 1 3}$ & $12,442,373$ \\
Pune & $\mathbf{6 9 6 . 7 6}$ & $\mathbf{4 1 8 . 6 3}$ & $\mathbf{2 3 3 . 6 4}$ & $\mathbf{4 4 . 4 9}$ & $3,124,458$ \\
\hline
\end{tabular}

All numbers are cases per million population, except population column

Bold indicates cluster of two cities having very high impact

Source: Developed based on data from the Census of India 2011 (for population); covid19india.org

in the selected megacities, with at least 20 times the number (from confirmed cases to deceased) as compared with Bengaluru, indicating the massive challenges these cities are going to face. Hence, our focus is on Mumbai-the city where the action research pilot was undertaken-in this study (Table 1).

Having waited patiently for the year 2020 - the milestone year of Vision 2020 by the most popular president of India, Dr. A. P. J. Abdul Kalam (e.g. Kalam and Rajan 2002)—the Group on Competitiveness (GoC) at IIT Bombay was overwhelmed by such a tsunami, but recovered quickly to stand up again and start walking. With students having to leave labs and campus, and offices under threat of lockdown, it was considered wise to shift the base of the GoC to home. Thinking soon started on ideas to preserve food and information and communications technology (ICT) infrastructure for digital work.

The first pilots were on the research front, where a commitment was made to continue research, and even do much better than last year in terms of output. Several initiatives were established, involving members, for the evolution of 'Return from COVID-19'. Only a glimpse of one such project is given in the Appendix. Let me list key learnings here:

- As we started rationing food, we realized how much wastage we had. We hope to cut monthly expenses by at least $40 \%$.

- We do not necessarily require so many physical assets such as buildings and cars. We have started pilots to test efficiency with much less asset use with minimum forex. Such steps can help us on a path towards better balance, if not 'आत्मनिर्भरता' that is recalled in crisis.

- Balance is important, as we swing from physical to digital; otherwise unexpected effects may occur, and worsen the situation. For instance, e-learning is picking up massively in COVID-19 times. Even though some focal institutes in India are capable of creating relevant local content and exchanging it to earn some forex, the net forex and trade competitiveness index (TCI) can go markedly negative as the costs of digital platforms can rise stead- 
ily. As there are business oligopolies in the USA (e.g. the Big Five tech companies, Rayport et al. 2019), costs can be very high. Because concepts such as Swadeshi take too long to diffuse (and penetrate in India, unlike in the USA/EU/East Asia), many institutes or universities can become stranded in high-risk zones of digital dependence without affordable indigenous options. The side effects such as lifestyle diseases and digital addiction that many of can get into may require massive doses of bitter treatments (e.g. digital detox) to return to a normal condition.

- There is so much to be done from a researcher perspective to learn from crisis and pilots. One of the things we focused on was a platform called the International Journal of Global Business and Competitiveness (JGBC). We contacted many members of the editorial board, review board and authors to reconnect and link with emotionally. Based on suggestions received, work has started on improvements on regular issues and on several supplementary or special issues, including one related to COVID-19.

\section{Emerging Topics of Further Studies and Actions}

We clustered emerging topics of high importance in two sections for quick attention of leaders.

\section{Narrow Domains of Business and Management}

- Many businesses have seen massive erosion of the top line, with grave implications for profits, corporate social responsibility (CSR) and sustainability activities. Other businesses have or may fold. In such situations, the survival facet of competitiveness becomes crucial. Starting from survival of oneself (from such viruses or other infectious pathogens) and family, employees, suppliers and local stakeholders should get higher priority. The factors and criteria of competitiveness (Momaya 2001) that become more useful in such a crisis era can be an urgent topic for study.

- People are the heart of business. Studies that address questions such as the following can be useful:

- How can employees be motivated to evolve productive and healthy work schedules and environment, while keeping morale of family members high?

- How can they be enabled digitally for task delivery, cooperative work and even speed learning of essential skills? What are the trends in the availability of affordable indigenous tools for that?
- Capabilities and the maturity of people are tested in such trying times. Even when managers are less mature, top leaders need to demonstrate resilience, restraint and responsibility. How do frameworks such as P-CMM [people-capability maturity mode] (e.g. Ambastha 2013) need to be adapted for such a crisis?

- Leadership in discontinuity is a very different ball game. Popular theories and frameworks in developed countries are often not working in their own countries; expecting them to work in complex emerging countries such as India is less realistic, even after adaptation. For instance, the healthcare system in India is highly fragmented and fragile. How do we rebuild more internationally competitive and flexible systems that provide exciting opportunities for study and action pilots? Here, concepts such as lean or agile development or start-up can be tested.

- On a different plane, leadership in discontinuity needs to be quite creative and one that forges 'human cooperation', perhaps the most powerful force on this planet (Kalam and Tiwari 2015). How can we cultivate such leaders and how can we evolve cooperative strategies (e.g. Momaya 2008) remain an exciting perennial topic?

- Megacities such as Mumbai and Pune may have to bear the worst, as densities are high or growing rapidly. They may run out of leaders who are capable of rebooting MSMEs and firms to restart supply chains. The situation may be tougher for Mumbai, as its value chains and industry value system are less digitized, for example with respect to Bengaluru. Questions such as how to redirect one's thinking towards more sustainable systems-e.g. decongestion for flexibility to face larger crises-can provide exciting opportunities for study.

- MSMEs are worst hit by the discontinuity, but one with a competitiveness orientation can survive and rebound. Many SME exporters do not have money even to pay wages, and their supply chains need to be rebooted in the face of very limited resources, including cash flow and other financial assets. Trust plays a key role in such trying times. Identifying, selecting and reviewing best practices in local contexts can provide useful learning (for examples from India, see CII 2020 bp).

- Prolonged lockdowns and related uncertainty are testing the mettle of even enduring industrial houses, and SME sustainability will require outside-the-box ideas and actions. Studies that explore best or next practices of sustainability in both the near and long term can be very useful.

- Goals such as 'स्वस्थ समुह' (healthy groups), institutes and cities demand paradigm shifts to break out from vexing myths. Balance between 'उपचार एवं व्यापार' is difficult to define and evaluate, but provides exciting topics of research for some exceptionally enduring researchers. 


\section{Broader Policy Domains}

Globalization has received a major blow due to the crisis. While several countries including China and Korea are flexible enough to redirect their focus, studies are needed to understand issues such as what can be done by large emerging countries such as India to reboot their export supply chains to meet the urgent need for medical supplies, food, and other humanitarian needs of poorer countries.

- Repeated pump-priming of the financial system is leading to precarious economies in many countries. Time will demand cooperative strategies, particularly between large democratic countries such as India and Japan, in banking, financial services, insurance, manufacturing and emerging industries (e.g. Bansal et al. 2010; Momaya 2008, 2016).

- While market forces in entrepreneurial countries such as India may like to densify cities to the hilt, not all cities can sustain such growth as Mumbai. What policy should guide population stabilization in urban areas for sustainable transformation? How can pilots such as 'Provision of Urban Amenities to Rural Areas (PURA)' be upgraded for new situations?

- How can we define and measure the competitiveness of cities to withstand such strategic discontinuities? What can we learn from Seoul, Tokyo or other cities that have demonstrated higher resilience?

\section{Concluding Remarks}

Every crisis provides clues that can translate to opportunities for action, if proactive individuals and firms are open to listening to weak signals (Schoemaker and Day 2009). The COVID-19 crisis is similarly providing clues to enormous opportunities for building health and values such as discipline to cope with a discontinuity. India had never faced such a challenge of a potential loss of thousands of lives despite efforts by so many, but the country has responded quite well to government calls for collective initiatives such as the Janata curfew (Swayam-shisht). Institutes such as IIT Bombay also responded proactively for safety of thousands of students and implemented lockdowns, while many faculty also proactively began working from home. The core contribution of this article-extending a flexible paradigm to address issues arising from strategic discontinuities-also evolved from pilots in crisis times.

Let me give a glimpse of an action agenda for associates and readers of JGBC from the learning from pilots. When facing issues regarding balance in nutrition, it is still possible to increase immunity - a key defence for coping with viruses such as coronavirus or anything else that may follow. Practices such as 'य़ोग और प्राणायाम' (yoga and pranayam) can help improve our health to face such crises. Since the crisis has exposed the limitations of so-called global supply chains (GSCs) (e.g. Griffith and Myers 2005), we must learn to take help from local supply chains, even when we cannot ride off the GSCs. For those keen to evolve their research for the post-COVID-19 era, I urge them to evolve linkages-at the early stage of research conceptualization-of the problems of functional areas (e.g management, operations, HR, finance) with the needs of competitiveness, as thousands of micro, small and medium enterprises (MSMEs), ventures, start-ups and even established firms will struggle to survive due to gaps in their understanding about competitiveness.

While collective bottom-up initiatives take time to surface, the power of individual efforts should not be underestimated. For instance, most of the innovative firms in Japan were born from such passionate individuals and teams during the crisis of WW II. We hope to bring you more exciting stories about the return from COVID-19 to next steps in the coming issues of JGBC. Until then, visit regularly or follow our micro-projects (e.g. on ResearchGate) to receive updates about calls for papers (CfPs), seminars, boot camps and other action workshops.

Let me close this perspective editorial by refreshing our collective memory with the words of the great saint Tiruvalluvar, in the current context:

Those who strive with strong unwavering mind will leave misfortune's fate behind.-Tirukkural (verse 620; Tiruvalluvar 2000)

\section{Key Questions}

The topic of 'Revitalise from Viruses' is very vast; we will focus on questions related to internationalisation and export competitiveness. This can spark different thinking and learning that can be implemented in relevant time horizons, including today. Please reflect on these questions or suggestions in context of small organizational unit in your firm or other export-oriented firm of your choice.

1. Accepting such crisis due to virus or other pathogens (विषाणु) as a new normal, evolve a plan to help yourself, family, friends and other groups to live with it safely. Learn to evolve safety norms and processes (e.g. use of Apps such as Arogya Setu, when going closer to risky zones) to enhance protection and options to recover faster, when caught by the pathogen.

2. Plethora of guidance and 'rules or regulations' coming from different bodies can create a lot of complexity and 
chaos. Try to simplify your choices and processes to minimize adverse impacts on productivity and quality.

3. Plan pilots to increase sustainability of your activities by thinking such as glocal (global thinking with local sustainable actions).

4. Review patterns of forex spend and earning to calculate trends of net forex and trade competitiveness index (TCI) for the firm. Generate ideas and start pilots to improve net forex.

5. Explore projects on "Return from Viruses" to open dialogue with professionals who are trying to share their views, resources and research on the topic and link such projects with other similar projects to enhance awareness, immunity and revitalise self and others.

Acknowledgements Our sincere thanks to anonymous reviewers for constructive suggestions for improvement. I acknowledge active participation of researchers Padmanav Adhikari, Sneha Bhat, interns Harshil Misra, Neha Tale, Chaitanya Johari, Rishabh Thapliyal and other members of the Group on Competitiveness (GoC), IIT Bombay in the pilot. We thank SJM School of Management for infrastructure support. Partial financial support for activities related to this research from Wadhwani Foundation through Industrial Research and Consultancy Centre (IRCC), Indian Institute of Technology Bombay is acknowledged.

\section{Appendix}

\section{Findings from a Pilot of 'Return from COVID-19' at a School Level}

This section gives a glimpse of extending a popular approach, situation-actors-processes-learning-action-performance (SAP-LAP, Sushil 2001) by applying it to a challenging context of crisis. We contribute to the method by 'lean application' of the framework for a micro-context. Here is just a glimpse of elements of SAP-LAP analysis.

\section{SAP-LAP Analysis of Impact of COVID-19 at a School Level (Focusing on role of bottom-up actions)}

\section{Situation}

\section{Macro}

- Unprecedented lockdown disrupted supply chains

- Countries' fragile export portfolios may even get wracked further towards commodity exports
Micro

- Abrupt disruption to academics due to lockdown

- Less prepared associates; e.g. with their access to hardware, software

- Access to lab not possible during lockdown

- Ambitious plans for 2020, but disruption and dispersion of team

- Less availability of indigenous sustainable tools (or time for their adaptation)

\section{Actors}

- Researchers (Ph.D. scholars, master students, interns, undergraduate students)

- Faculty (core, adjunct and visiting)

- Institute management

- Governments (municipal, state and central)

- Staff

- Civil society

\section{Processes}

- Government-initiated

- Janata Sanchar-bandi to sensitize (March 22)

- Lockdown for 3 weeks (from March 24)

- Suspension of transport systems (e.g. trains, planes)

- Bottom-up; e.g.

- Inspired by the 'Group on Competitiveness' (GoC)

- Inspiration from initiatives such as biathlon that aimed high

- Competitiveness pioneers

- Faculty that practice regularly

- Faculty that take initiatives

- Coaches that thought long term

\section{- Associates suggested}

- Internships in e-mode

- Pilots for practices (e.g. yoga or pranayam or fitness) at their home town

- Faculty mentored

- Online review meets

- Micro-blog 


\section{Learning}

\section{Macro: (e.g. for School)}

- First such lockdown in short school history crippled basic functions, e.g. office became less responsive

- Gaps in Silver Jubilee plans exploded; significant drop in activities, e.g. due to suspension of activities, classes, management development programs (MDPs)

\section{Micro: (Focus on Group on Competitiveness)}

- Proactive actions helped shift office to home

- Strategy was initiated to minimize disruptions, e.g. by:

- Setting up digital pilot workbenches at home

- Associates who were quarantined during travel were energized

- Papers were submitted on time

\section{Action}

- Identifying and listing of lakshman rekhas

- Launch of project with minimum viable support

- Identifying and selecting healthy associates

- Launch of early micro-blogs

- Sharing of responsibilities for updates

- Listing precautions to minimize local rebounds of COVID-19

\section{Expected Performance to Aspirations}

- Positive response from ( $>80 \%)$ associates

- Strong following by concerned students (e.g. beyond IITs)

- High percentage of associates open to plan return (e.g. 50)

- Consent from open faculty

- Rebooting pilot studies

- Entry in local competition

\section{Alternative Micro-situation (Horizon 1-2 years)}

\section{- An optimistic scenario}

- Faculty propose challenge projects to reboot activities and take new projects, e.g. e-seminars (later e-MDPs with face-to-face components and boot camp)

- Alternative gemba piloted close to residences to minimize transport disruptions with testing for creative nature-friendly space for several weeks; elements of sustainability of such lab are being identified and characterized

- Digitalization and experience of virtual work may reduce load on physical infrastructure, permitting more executives to be associated

- Cooperative head involves key stakeholders to evolve better strategic intent

- Digitally savvy associates ready to facilitate e-learning to face such abrupt disruption to academics due to lockdown

- An enduring associate trained to handle less prepared associates; e.g. with their issues related to hardware (HW), access to software (SW)

- Pilots of alternative labs done to learn when access to lab is not possible during lockdowns

- Even higher goals (at least 20\% high in 2020 and 50\% high in 2021 over 2019 levels, particularly in terms of research output) are set to see that the ambitious plans for 2020 are NOT disturbed even with dispersion of the team

- Two associates trained to do pilots to address less availability of indigenous sustainable tools (or time for their adaptation)

The above 1- to 2-year example scenario of the situation is quite short-term, mainly focusing on firefighting. We need to also work a bit on medium- and long-term (e.g. 6-10 years) scenarios when the focus can be on structural factors of competitiveness of groups that demand such horizons.

\section{References}

Ambastha, A., \& Momaya, K. (2004). Challenges for Indian software firms to sustain their global competitiveness. Singapore Management Review, 26(2), 65-78.

Ambastha, A. (2013). Building competitiveness through people CMM: a case of implementation in tata capital. International Journal of Global Business and Competitiveness, 8(1), 52-57.

Bansal, P., Vallaturu, V. K., \& Bansal, V. (2010). Exploring cooperative strategies between India and Japan: a view on banking industry. International Journal of Global Business and Competitiveness, $5(1), 1-13$.

Bhattacharya, S., Momaya, K., \& Iyer, K. C. (2009). Enablers of sustaining competitiveness: a case of growth strategies of top international construction companies. Global Business Review, 10(1), $45-66$.

CII (2020) Competitiveness of India Inc.-India @ 75: Forging ahead, confederation of Indian Industry. https://www.cii.in/NationalTh eme.aspx ?enc $=$ ns9fJzmNKJnsoQCyKqUmaQ. Accessed 27 Jan 2020

Davison, R., Martinsons, M. G., \& Kock, N. (2004). Principles of canonical action research. Information Systems Journal, 14(1), $65-86$. 
Deshmukh, S. G. (2016). Manufacturing competitiveness: research opportunities. International Journal of Global Business and Competitiveness, 11(1), 1-6.

FICCI (2020) Note of Exit strategy of lockdown, Federation of Indian Chambers of Commerce and Industry (FICCI)

गांधी मोहनदास करमचंद (१९२१), नानवटी अमृतलाल ठाकोरदास (अनुवादक), हिन्द स्वराज्य, सर्व सेवा संघ-प्रकाशन, राजघाट, वाराणसी।

Gandhi, M. K. (1960). Trusteeship. Ahmedabad: Navajivan Trust Publication.

Griffith, D. A., \& Myers, M. B. (2005). The performance implications of strategic fit of relational norm governance strategies in global supply chain relationships. Journal of International Business Studies, 36(3), 254-269.

Kalam, A. P. J., \& Rajan, Y. S. (2002). India 2020: a vision for the new millennium. London: Penguin Books.

Kalam APJ, Tiwari A (2015) Transcendence: my spiritual experiences with Pramukh Swamiji, Harper Element, New Delhi.

Kemmis, S., McTaggart, R., \& Nixon, R. (2013). The action research planner: doing critical participatory action research. Berlin: Springer Science \& Business Media.

Meadows, D., Randers, J., \& Meadows, D. (2004). Limits to growth: The 30-year update. Hartford: Chelsea Green Publishing.

Mittal, S., Momaya, K. S., \& Agrawal, S. (2013). Longitudinal and comparative perspectives on the competitiveness of countries: learning from technology and the telecom sector. Journal of CENTRUM Cathedra: The Business and Economics Research Journal, 6(2), 235-256. https://doi.org/10.7835/jcc-berj-2013-0090.

Momaya, K. S. (2001). International competitiveness: Evaluation and enhancement. New Delhi: Hindustan Publishing Corporation.

Momaya, K. S. (2008). Evaluating country competitiveness in emerging industries: learning from a case of nanotechnology. Journal of International Business and Economy, 9(1), 37-58.

Momaya, K. S. (2016). City clusters and break-out in corporate competitiveness. Competitiveness Review, 26(4), 415-434. https://doi. org/10.1108/CR-08-2014-0021.

Momaya, K. S., Bhat, S., \& Lalwani, L. (2017). Institutional growth and industrial competitiveness: exploring the role of strategic flexibility taking the case of select institutes in India. Global Journal of Flexible Systems Management, 18(2), 111-122. https://doi. org/10.1007/s40171-016-0144-2.

Momaya, K. S. (2019). The past and the future of competitiveness research: a review in an emerging context of innovation and EMNEs. JGBC, 14(1), 1-10. https://doi.org/10.1007/s42943-01900002-3.

Porter, M. E. (1990). The competitive advantage of nations: with a new introduction. Free Press.
Rayport J. F., Kelley J, Schwalb N (2019) The Powers that Be: Google, Apple, Facebook, Amazon, and Microsoft, Harvard Business School.

Sahoo, T., Banwet, D. K., \& Momaya, K. (2010). Strategic technology management in practice: dynamic SAP-LAP analysis of an auto component manufacturing firm in India. Global Journal of Flexible Systems Management, 11(1-2), 13-23.

Schoemaker, P. J., \& Day, G. S. (2009). How to make sense of weak signals. MIT Sloan Management Review, 50(3), 81-89.

Shee, H., \& Momaya, K. (2001). Flexibility and competitiveness: case of software/services firms in India. Global Journal of Flexible Systems Management, 2(4), 33.

St, T., \& Krishnamoorti, N. (Eds.). (2000). Saint Tiruvalluvar and his message of life as Dharma. Chennai: Vivekananda Kendra Prakashan.

Sushil. (2001). SAP-LAP models. Global Journal of Flexible Systems Management, 2(2), 55-61.

Wong, L. H., \& Davison, R. M. (2018). Knowledge sharing in a global logistics provider: an action research project. Information Management, 55(5), 547-557.

Worldometers (2020). Worldometer Coronavirus Cases. https://www. worldometers.info/coronavirus/. Accessed 20 May 2020.

Yin, W., Moon, H. C., \& Lee, Y. W. (2019). The success factors of Korean global start-ups in the digital sectors through internationalization. International Journal of Global Business and Competitiveness, 2019, 1-12.

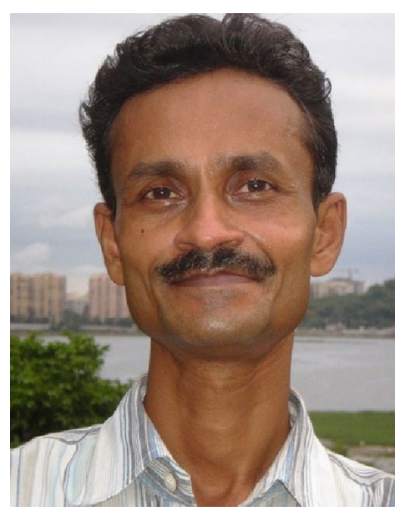

Kirankumar S. Momaya is a Professor of Technology Management and Competitiveness at SJM School of Management, IIT Bombay. His current topics of interest include the role of digital platforms, AI and other emerging technologies for competitiveness of firms, industries and clusters. His research has been published in Vikalpa, IIMB Management Review, Competitiveness Review, JSSPRM (Japan) and other leading journals of management or competitiveness in Asia or world. He serves on Editorial Board of growing journals of management from Asia such as JFSM, JAMR. He is the Past President of the Global Institute of Flexible Systems Management (2018-19). 